\title{
Acoustic Design of Buildings Using Mathematical Model Based on Sound Simulation
}

\author{
H. Esmaeil Yazdi ${ }^{1}$, A. M. Salehi²* \\ ${ }^{1}$ Construction Engineering and Management, Kharazmi University of Tehran, Tehran, Iran \\ ${ }^{2}$ Faculty of Engineering, Kharazmi University of Tehran, Tehran, Iran
}

\section{PAPER INFO}

Paper history:

Received 09 October 2021

Accepted in revised form 27 December 2021

\section{Keywords:}

Building acoustic design

Experimental design

Frequency

Linear model

Simulation

Sound intensity

\section{$A \begin{array}{lllllllllllll} & B & T & R & A & C & T\end{array}$}

Proper acoustic design is especially important in some buildings. For example, in concert halls, one of the desirable functional features is the proper transmission of music. In this regard, an indicator that can effectively show the quality of the received sound is the sound intensity, which is the purpose of this study is a way to optimize this indicator. Among the most effective variables that will affect the intensity of the received sound and also the important characteristics of the sound source are the frequency and octave of the sound, as well as the distance between the sound source and the receiver. In this research, a new method was proposed to investigate the effect of these three variables on the received sound intensity. In this regard, ODEON software, one of the most powerful software in acoustic design, was used and data analyses were implemented. Then, using full factorial method (one of the experimental design methods), targeted scenarios based on three independent variables were identified and by using the results of simulated scenarios, the linear relationship between the dependent variable (sound intensity) and independent variables (frequency, octave and distance) were developed. Using this linear relationship, it was found that the octave of sound has the greatest effect on sound intensity, and sound frequency and distance from the sound source were inversely related to the sound intensity.

\section{INTRODUCTION}

Applied science is the knowledge of the existence laws in order to achieve comfort and living with peace. On the other hand, buildings are a place of comfort, so it can be expected that most of the human efforts to build better and more scientific structures for themselves. Even today, determining the characteristics for more efficient and appropriate use of building is considered. Also, simulation techniques are used today in a variety of programs designed to enhance the skills of health care providers [1-4].

A building envelope plays a key role in controlling the internal environmental conditions. Mohsen Alturshan [5] conducted acoustical noise reduction analysis for the transmission of noise through partitions. In this research, the effect of a brick wall containing a single pane of glass and a compound pane of glass studied on the reduction in sound pressure level. Also, the noise transmitted and reflected at normal incident through a non-distorting wall simulated. The results indicated, the merits of the various methods that could be used to achieve the reduction of noise transmission.

Acoustic optimization of building space is a complex and at the same time essential design process that is associated with many complexities $[6,7]$. In concert halls, the most important issue is the proper transmission of sound to the listener and the audience. Improper reception and unbalanced sound intensities will question the use of the concert hall and the result of the musicians' work, and can create problems for the halls and the audience.

Prolonged, loud noise can damage the delicate ciliated cells of the cochlea and the nerve endings in the inner ear, resulting in permanent and irreversible sensorineural hearing loss. This hearing loss can be accompanied by tinnitus. Exposure to loud noise is the most important cause of hearing loss because people usually do not follow safety principles. In fact, the

\footnotetext{
*Corresponding Author Email: am_salehi@khu.ac.ir (A. M. Salehi)
} 
universal unit for sound measurements is decibel $(\mathrm{dB})$; as sound is a wave with defined frequencies. Sounds with a volume of more than 80 decibels and constantly in accordance with the situation that usually exists in concert halls, can injure the ear. The limit of serious sound damage to the human ear is 110 decibels and sounds higher than 130 decibels, even in a short time, quickly damage the cochlear hair cells irreparably. Hearing loss develops gradually due to long, loud noise and is usually not noticeable to the person $[8,9]$. The results of Bozkurt and Demirkale [10] research in 2017 showed that the sound environment has a physiological and psychological effect on human health and is also very important in creating comfortable conditions. Accordingly, a healthy environment and a better quality of life depend on environmental noise control.

Given the above issues, as well as the requirement to have a minimum of sound intensity, determining the appropriate acoustic conditions in concert halls is very important. In Iran, the issue of eighteen national building regulations has been developed to create design criteria and acoustic analysis of different spaces [11].

In 2002, the National Standards Institute of the United States designed standards for executive standards and acoustic design needs of concert halls and other spaces, which were edited in 2009. In Iran, eighteen national building codes have been developed to establish criteria for acoustic design and analysis of various spaces.

The sharpness and clarity of sound related to hearing the components of a sound depends on the clarity and power of the sound. Sounds can take many forms, such as conversation, music, loud shouting, the sound of machines, and so on. The degree of sharpness of sound depends on the ratio of the amount of primary sound energy received to the secondary sound energy received, which is called sound intensity [8].

In an open space, the normal speech level at a distance of one meter is between 55 and 65 decibels. Under certain conditions, the speech level can be at least $30 \mathrm{~dB}$ and the maximum shouting level can be up to $96 \mathrm{~dB}$. According to investigation conducted by Sutherland and Lubman [9], about $15 \%$ of women cannot raise their voice above 75 decibels, while the volume level of some men can easily reach to 96 decibels or even 104 decibels. Statistics showed that it is very difficult to understand the clarity of speaking with a shout. In addition, if in a normal speech, the level of sound that reaches the listener is higher than 80 decibels, a lot of pressure will be applied to the ear.

Research on how sound is propagated indoors is very limited. Some of the research related to sound insulation in buildings is as follows. Based on research conducted by Alonso et al. [12], it was found that to improve sound insulation, it is concluded that there is no global consensus on external sound insulation and sound requirements around the world. On the other hand, the proper performance of sound insulation in building elements depends on the level of external sound or the level of internal noise. The results also showed that the performance of windows against sound can be highly effective when external noise is limited to 60 decibels.

Dissanayake et al. [13] in 2021 Developed a new method for creating sound insulation materials using cotton/polyester waste and natural rubber. In this study, acoustic properties based on sound absorption coefficient (SAC) and noise reduction coefficient (NRC) of materials used were investigated using an impedance tube device [6]. In the research of Glé et al. [14] in 2021, Experiments were performed under controlled conditions using sound intensity measurement method on 22 different samples to investigate the effect of thickness, wood formwork, coating with different levels. The research results showed that with this method, the performance of surfaces in the building can be predicted satisfactorily [15].

Accordingly, the intensity is a very important parameter to determine the volume of sound, which is very important in concert halls. For this purpose, in this study, the effectiveness of variables such as: frequency, octave and distance that have the greatest effect on sound intensity, is investigated and a process for optimizing these indicators is discussed.

\section{RESEARCH METHOD}

The purpose of this study is to identify the effect of important variables on the clarity and intensity of received sound. For this purpose, the received sound intensity at a specific point was evaluated. In this regard, first a concert hall was modeled in the software space, then the received sound intensity was determined according to the distance of the receiving point from the sound source, frequency and octave of the sound source.

\section{Case study}

In this study, the famous Boston Concert Hall, shown in Figure 1, was simulated in software. This hall is 20 meters wide and 50 meters long. Engineers have come to the conclusion that halls that look like shoe boxes have the best acoustic properties for concerts, and it can be seen that this hall also has this architectural form. The threedimensional space of the Boston Amphitheater consists of 428 distinct levels that the various levels affect the way the sound is distributed. In this case study, the absorption coefficient of 0.1 is chosen.

\section{Dependent and independent variable}

\section{Sound intensity}

Sound intensity, or acoustic intensity, is the energy carried by sound waves per unit area, a variable that indicates the power of the received sound. Table 1 shows the received sound intensity for different audio sources.

The loudness of the sound depends on the ratio of the amount of primary sound energy to the secondary sound energy, which is called sound intensity. Sounds that have 
Table 1. Volume in different modes

\begin{tabular}{|c|c|}
\hline Audio source & Sound intensity (dB) \\
\hline Silence & 0 \\
\hline Normal breathing & 10 \\
\hline Whispers & 30 \\
\hline Conversations in one meter & 40 \\
\hline Relatively long conversations & 60 \\
\hline Washing machines & 70 \\
\hline Vacuum cleaners & 80 \\
\hline Trucks in 5 meters & 90 \\
\hline Rock Concert & 110 \\
\hline Ambulance sirens & 120 \\
\hline Jet engines & 140 \\
\hline Shots fired & 160 \\
\hline
\end{tabular}

a volume of more than 80 decibels can be harmful to the ear, and it is difficult to hear sounds that have a volume of less than 30 decibels. In general, it can be said that sounds with an intensity of 50 to 70 decibels are suitable for concert halls.

\section{Frequency}

Frequency is the number of oscillations of a sound wave per unit time. It is one of the most important characteristics of sound produced by an audio source, and the higher the frequency of sound, the more energy it loses if it vibrates in the environment, and the audio receiver is expected to intensify that sound. The human ear hears sounds with a frequency between 20 and 20,000 $\mathrm{Hz}$. Sounds with a frequency of 125 to $8000 \mathrm{~Hz}$ are considered for understanding speech but in acoustic designs, a frequency between 1000 and $4000 \mathrm{~Hz}$ is more important and examined. Also, by changing the frequency of sound using different tools, it can be used for applications such as crack size determination and corrosion status in metals $[16,17]$.

ODEON software also sets the frequencies of 1000 , 2000 and $4000 \mathrm{~Hz}$ to be tested by default, for this purpose, these three levels were considered to examine the effect of frequency.

If the source of sound wave propagates the waves uniformly in all directions, the sound is propagated as spherical waves in space. Now, if we assume that this point source of sound emits sound waves uniformly (same intensity in all directions), simply by considering the hypothetical spheres with radius " $r$ " from the sound source, we can get all the energy that the sound source produces and calculate what passes through the surface of this sphere. So according to the relation $\left(\mathrm{I}=\mathrm{PA}\left(\mathrm{W} \cdot \mathrm{m}^{2}\right) \mathrm{I}\right.$ $\left.=\mathrm{PA}\left(\mathrm{W} \cdot \mathrm{m}^{2}\right)\right)$ the sound intensity that we feel around a point source is inversely proportional to the square of the distance from the source.

Therefore, the distance from the sound source will have a great effect on the intensity of the received sound. For this purpose, the position of the sound receiver at the point $(2.667,0.01,45.36)$ was considered and also the position of the sound source at the first level $(2.00,0.00$, 3.00) was considered. The distance to the receiver will be 42.365 meters, the position of the sound source in the second level $(2.00,0.00,8.00)$ was considered, the distance to the receiver will be 37.366 meters and the position of the sound source. The third level $(2.00,0.00$, 13.00) was considered, the distance to the receiver will be 32.367 meters.

\section{Octave}

An octave is the distance of two consecutive notes in an instrument, notes that are spaced one octave apart, the frequency of one of them will be twice that of the other. When it is said that a note is one octave higher, it means that this note is exactly the same as the previous note, except that it is played in a stronger area than the musical instrument. Therefore, the octave in which the note is played will have a great effect on the intensity of the received sound. In order to evaluate the effect of different octaves, for 1000 frequency and specific positions of the sound source and receiver, the sound intensity for octave one according to Figure 1 was $1.27 \mathrm{~dB}$ and for octave three according to Figure 2 was $5.99 \mathrm{~dB}$. Which shows a difference of 4.72 times, which indicates the large effect of octave on the received sound intensity.

\section{THEORY AND CALCULATION}

\section{Simulation}

Building simulation has been used to study various building performance, especially building energy consumption [8]. The building sound simulation is performed to determine the effect of various variables related to the sound source such as frequency and octave of sound, as well as the distance between the sound source and the receiving point on the sound resolution, which is measured by the sound intensity. In this regard, ODEON, which is one of the most practical and well-known acoustic design software, has been used. ODEON is one of the most powerful software in the field of acoustics. This program has good features including use of speakers and the ability to make speakers with desired specifications, has a variety of materials available to increase the accuracy of calculations, ability to check materials with diffusion coefficient and multiple absorption coefficients, calculate all acoustic parameters, Identify weaknesses in acoustic design and compatible with AUTO-CAD software. 


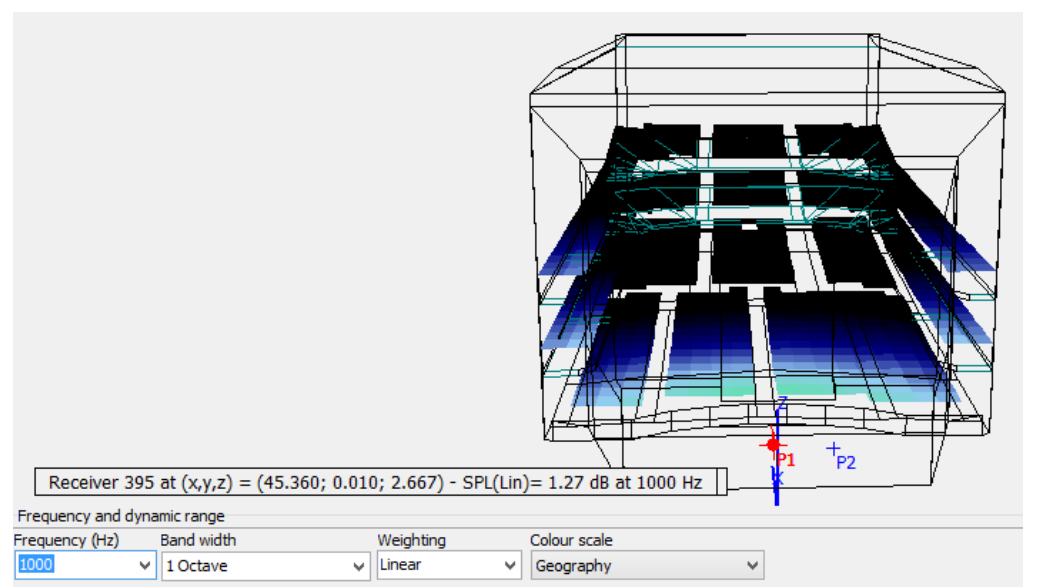

Figure 1. Sound distribution with frequency 1000 and octave 1

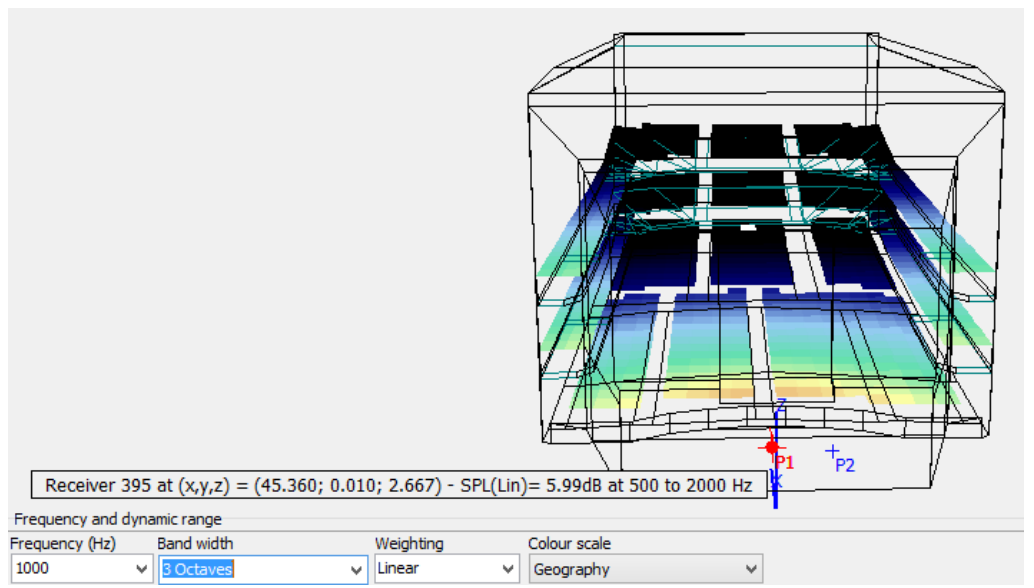

Figure 2. Sound distribution with frequency 1000 and octave 3

In this research, ODEON 15.15 was used. To simulate, first the details of the interior and exterior of the hall architecture are drawn in the software, then the material, the position of sound sources and receivers are defined, all surfaces were rough concrete that have scatter of 0.1 . Based on this information such as sound intensity at different points, reverb, sound absorption by Different levels, how to play audio, etc. are specified as software output. For this purpose, after drawing the architectural space of the hall, the position of the sound source was determined at points with coordinates $(2.00,0.00,3.00)$ meter, in the next steps of modeling the coordinates of the sound source $(2.00,0.00,8.00)$ meter and $(2.00,0.00$, 13.00) meter were placed. Receiver point coordinates $(2.667,0.010,45.360)$ meter were also determined. Then the absorption coefficient of different surfaces was assigned. Hard surfaces reflect sound waves, and many of these types of surfaces can be seen in concert halls. Unlike hard surfaces (walls), soft surfaces absorb more acoustic waves. In the hall, only soft surfaces are used in chairs, and surfaces with low absorption coefficients are used that not suitable for main surfaces and walls.

\section{Modeling}

Making changes to the simulated case study and performing the analysis is time consuming and complex, and the number of factors such as noise, pick-up time, sound translocation, seat arrangement is high, therefore determining their desired values is complicated by performing multiple simulations. Turning the simulation space into a mathematical model based on the object can help to do the right design.

Linear model is considered as simulation information modeling method in this research due to its simplicity and at the same time many applications. For this purpose, the distance from the sound source, frequency and octave of sound were determined as independent variables and the sound intensity was considered as a dependent variable.

\section{Experimental design}

Experimental design is a scientific approach that allows researchers to gain knowledge to better understand a process as well as determine how inputs affect outputs. Different Experimental design methods are used in various fields of engineering, including energy efficiency 
and determining the optimal method of wastewater treatment $[18,19]$. In this research, full factorial method has been used to develop the linear model. In this regard, for all three independent variables, including frequency, octave and distance, three levels were considered (Table 2). Using the complete factorial method, the number of scenarios for developing a linear relationship is $3^{3}=27$ scenarios.

Minitab software was used for statistical analysis including experimental design and linear model development. Minitab software is one of the best statistical software that has special capabilities in some fields of statistics, including the application of statistics in industry and economics. The version of Minitab has been 19. In Minitab software, the dependent variable is sound intensity and independent variables are frequency, distance and octave of sound. Then, based on full factorial method and linear regression, all scenarios and linear model was developed.

\section{RESULT AND DISCUSSION}

\section{Simulation results}

By using Minitab software to develop a linear model from full factorial experiment design method, the required number of scenarios was determined. The variables and their levels are given in Table 3. these scenarios were obtained in ODEON software related to each combination and the result of simulation is shown in Table 3.

According to the results, the change in the considered variables caused a change in sound intensity from 0.91 to $9.29 \mathrm{~dB}$, which causes a change of about $8.38 \mathrm{~dB}$.

\section{Linear modeling}

Based on the scenarios designed by full factorial method, and simulation of the values of independent variables in ODEON software, the results were determined to develop a linear model. Accordingly, the linear model of sound intensity is as described in Equation (1).

$$
\begin{aligned}
& S=-0.000521 . F+2.2756 . O-0.2551 . D- \\
& 10.549
\end{aligned}
$$

where $\mathrm{S}$ stands for sound intensity and $\mathrm{F}$ is known as Frequency, $\mathrm{O}$ for Octave and D is for Distance.

In order to confirm the linear model and verified the obtained coefficients, the results obtained from ODEON software were compared with the result of linear model,

Table 2. Independent variables and its levels

\begin{tabular}{lccc}
\hline Variables & Level 1 & Level 2 & Level 3 \\
\hline Frequency & 1000 & 2000 & 4000 \\
Distance & 32.367 & 37.367 & 42.367 \\
Octave & 1 & 2 & 3 \\
\hline
\end{tabular}

Table 3. Selected scenarios for linear model development and

\begin{tabular}{|c|c|c|c|c|}
\hline Scenario & $\begin{array}{l}\text { Frequency } \\
\text { (F), } \mathbf{H z}\end{array}$ & $\begin{array}{l}\text { Octave } \\
\text { (O) }\end{array}$ & $\begin{array}{c}\text { Distance } \\
\text { (D), } \mathrm{m}\end{array}$ & $\begin{array}{c}\text { Sound } \\
\text { intensity, } \mathrm{dB}\end{array}$ \\
\hline 1 & 1000 & 1 & 42.365 & 1.27 \\
\hline 2 & 1000 & 2 & 42.365 & 4.16 \\
\hline 3 & 1000 & 3 & 42.365 & 5.99 \\
\hline 4 & 2000 & 1 & 42.365 & 1.03 \\
\hline 5 & 2000 & 2 & 42.365 & 3.61 \\
\hline 6 & 2000 & 3 & 42.365 & 5.61 \\
\hline 7 & 4000 & 1 & 42.365 & 0.12 \\
\hline 8 & 4000 & 2 & 42.365 & 1.75 \\
\hline 9 & 4000 & 3 & 42.365 & 4.42 \\
\hline 10 & 1000 & 1 & 37.366 & 2.38 \\
\hline 11 & 1000 & 2 & 37.366 & 5.29 \\
\hline 12 & 1000 & 3 & 37.366 & 7.11 \\
\hline 13 & 2000 & 1 & 37.366 & 2.17 \\
\hline 14 & 2000 & 2 & 37.366 & 4.8 \\
\hline 15 & 2000 & 3 & 37.366 & 6.77 \\
\hline 16 & 4000 & 1 & 37.366 & 1.37 \\
\hline 17 & 4000 & 2 & 37.366 & 3.13 \\
\hline 18 & 4000 & 3 & 37.366 & 5.69 \\
\hline 19 & 1000 & 1 & 32.367 & 3.65 \\
\hline 20 & 1000 & 2 & 32.367 & 6.57 \\
\hline 21 & 1000 & 3 & 32.367 & 8.39 \\
\hline 22 & 2000 & 1 & 32.367 & 3.47 \\
\hline 23 & 2000 & 2 & 32.367 & 6.15 \\
\hline 24 & 2000 & 3 & 32.367 & 8.09 \\
\hline 25 & 4000 & 1 & 32.367 & 2.78 \\
\hline 26 & 4000 & 2 & 32.367 & 4.68 \\
\hline 27 & 4000 & 3 & 32.367 & 7.13 \\
\hline
\end{tabular}
sound intensity simulation results

which is presented in Table 4. To evaluate the accuracy of the developed linear model, the results of the linear model and the simulation results are plotted in Figure 3, and by linear fitting, the accuracy of the model is evaluated. As can be seen with a coefficient of $\mathrm{R}^{2}=0.978$, the slope of the fitted line is 0.968 and the width of the origin is 0.275 .

\section{Effective parameters}

According to the results, because the frequency and amplitude of the oscillation are inversely related to each other, higher frequency sounds will oscillate more between the sound source and the receiver, and their energy will be reduced and the received sound intensity will be lower. In this modeling, the sound intensity has a 
Table 4. Model validation results with simulation results

\begin{tabular}{|c|c|c|c|c|c|}
\hline Scenario & $\begin{array}{c}\text { Frequency } \\
(\mathbf{F}), \\
\text { Hz }\end{array}$ & $\begin{array}{c}\text { Octave } \\
\text { (O) }\end{array}$ & $\begin{array}{c}\text { Distance } \\
\text { (D), } \\
\text { m }\end{array}$ & $\begin{array}{c}\text { Sound } \\
\text { intensity, } \\
\text { dB - } \\
\text { simulation }\end{array}$ & $\begin{array}{c}\text { Sound } \\
\text { intensity, } \\
\text { dB - linear } \\
\text { model }\end{array}$ \\
\hline 1 & 500 & 1 & 39.157 & 2.05 & 2.58 \\
\hline 2 & 500 & 2 & 39.157 & 5.02 & 4.85 \\
\hline 3 & 500 & 3 & 39.157 & 6.81 & 7.13 \\
\hline 4 & 1000 & 1 & 39.157 & 1.97 & 2.31 \\
\hline 5 & 1000 & 2 & 39.157 & 4.87 & 4.59 \\
\hline 6 & 1000 & 3 & 39.157 & 6.69 & 6.87 \\
\hline 7 & 2000 & 1 & 39.157 & 1.75 & 1.79 \\
\hline 8 & 2000 & 2 & 39.157 & 4.36 & 4.07 \\
\hline 9 & 2000 & 3 & 39.157 & 6.34 & 6.34 \\
\hline 10 & 500 & 1 & 34.186 & 3.24 & 3.84 \\
\hline 11 & 500 & 2 & 34.186 & 6.21 & 6.12 \\
\hline 12 & 500 & 3 & 34.186 & 8 & 8.39 \\
\hline 13 & 1000 & 1 & 34.186 & 3.17 & 3.58 \\
\hline 14 & 1000 & 2 & 34.186 & 6.08 & 5.86 \\
\hline 15 & 1000 & 3 & 34.186 & 7.9 & 8.13 \\
\hline 16 & 2000 & 1 & 34.186 & 2.98 & 3.06 \\
\hline 17 & 2000 & 2 & 34.186 & 5.64 & 5.34 \\
\hline 18 & 2000 & 3 & 34.186 & 7.59 & 7.61 \\
\hline 19 & 500 & 1 & 29.225 & 4.32 & 5.11 \\
\hline 20 & 500 & 2 & 29.225 & 7.3 & 7.38 \\
\hline 21 & 500 & 3 & 29.225 & 9.09 & 9.66 \\
\hline 22 & 1000 & 1 & 29.225 & 4.56 & 4.85 \\
\hline 23 & 1000 & 2 & 29.225 & 7.48 & 7.12 \\
\hline 24 & 1000 & 3 & 29.225 & 9.29 & 9.40 \\
\hline 25 & 2000 & 1 & 29.225 & 4.39 & 4.33 \\
\hline 26 & 2000 & 2 & 29.225 & 7.1 & 6.60 \\
\hline 27 & 2000 & 3 & 29.225 & 9.02 & 8.88 \\
\hline
\end{tabular}

negative slope in terms of frequency, but the frequency does not affect the received sound intensity as much as other variables.

The received sound intensity is inversely related to the distance. The intensity of the received sound decreases with increasing distance and it is observed that the amount of octave of sound has a significant effect compared to other variables on the received sound intensity. Also, the octave and the received sound intensity have a direct relation. According to the results, octave has the most direct effect and distance has more effect than frequency.

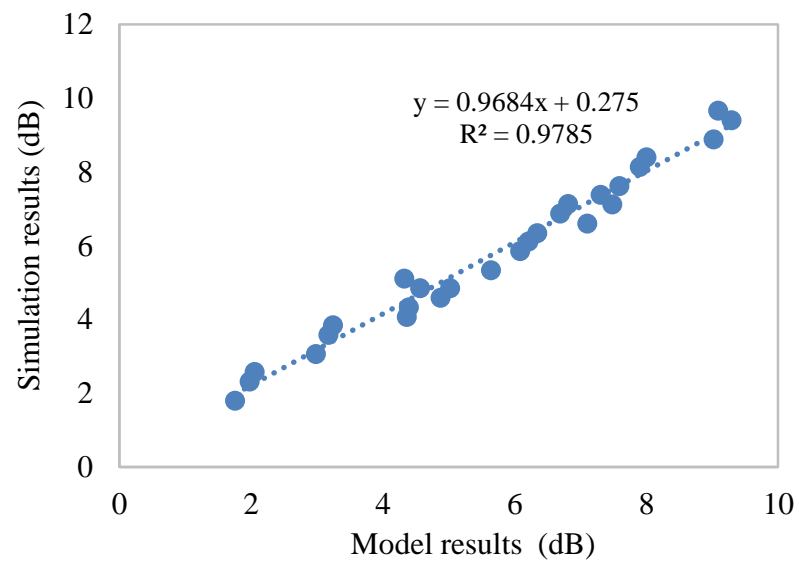

Figure 3. Dispersion distribution of model results and simulations for model validation

\section{CONCLUSION}

Optimizing the performance of buildings in terms of sound is very complex due to the influence of various factors. One of the most important ways to design audio is to use simulation software. But audio design optimization requires several scenarios that sometimes may not lead to optimal design. A good solution to take the path of optimal design is to convert the simulation space into a model with appropriate accuracy. To do this, using different experimental design methods (in this research full factorial method), targeted scenarios can be identified and by simulating these scenarios, the model can be developed with appropriate accuracy.

Accordingly, in the present study, for each of the three independent variables of research (frequency, octave and distance), three levels were considered. Nine scenarios were considered using the full factorial experimental design method. The designed scenarios were simulated in the ODEON software and the sound intensity results were determined for each scenario. Then the linear model of changes in sound intensity based on frequency, octave and distance was developed. Based on obtained results from this model, it was found that frequency and volume are inversely related to each other and octave has the greatest effect on the received sound intensity. Also, as it turns out, the intensity of the received sound is inversely related to the distance between the source and the receiver, which is shown by the developed linear model.

\section{DECLARATION OF INTEREST STATEMENT}

The authors declare that they have no known competing financial interests or personal relationships that could have appeared to influence the work reported in this paper. 


\section{REFERENCES}

1. Liu, J., and Landers, R., 2004. Integrated Modular Machine Tool Simulation for Education in Manufacturing Automation International Journal of Engineering Education, 20(4), pp.594611

2. Klopfer, E., and Squire, K., 2007. Environmental Detectives-the development of an augmented reality platform for environmental simulations. Educational Technology Research and Development, 56(2), pp.203-228. Doi: 10.1007/S11423-007-9037-6

3. Chalak Qazani, M.R., Asadi, H., and Nahavandi, S., 2019. A decoupled linear model predictive control-based motion cueing algorithm for simulation-based motion platform with limitted workspace. Proceedings of the IEEE International Conference on Industrial Technology, 2019(February), pp.35-41. Doi: 10.1109/ICIT.2019.8755051

4. Milton, M., Benigni, A., and Monti, A., 2019. Real-Time MultiFPGA Simulation of Energy Conversion Systems. IEEE Transactions on Energy Conversion, 34(4), pp.2198-2208. Doi: 10.1109/TEC.2019.2938811

5. Kadim Karim Mohsen Alturshan, 2018. Acoustical noise reduction technique. International Journal of Energy and Environment, 9(1), pp.2076-2909

6. Llorca Bofí, J., Redondo Domínguez, E., and Vorlaender, M., 2019. Learning room acoustics by design: a project-based experience. International Journal of Engineering Education, 35(1(B)), pp.417-423

7. Kapoulea, S., Psychalinos, C., and Elwakil, A.S., 2020. Fractionalorder shelving filter designs for acoustic applications. Proceedings - IEEE International Symposium on Circuits and Systems, 2020(October), pp.1-5. Doi: 10.1109/ISCAS45731.2020.9180640/VIDEO

8. Everest, F., and Pohlmann, K., 2015. Master handbook of acoustics. McGraw-Hill Education.

9. Sutherland, L.C., and Lubman, D., 2004. Development and challenges of the American National Standards Institute standard for classroom acoustics. Seminars in Hearing, 25(2), pp.167-177. Doi: 10.1055/S-2004-828667/ID/2

10. Bozkurt, T.S., and Demirkale, S.Y., 2017. The field study and numerical simulation of industrial noise mapping. Journal of
Building Engineering, 10.1016/J.JOBE.2016.11.007
9, $\quad$ pp.60-75.
Doi:

11. Iranian National building standard code 18 , Insulation and sound regulation in the building, 2018.

12. Alonso, A., Suárez, R., Patricio, J., Escandón, R., and Sendra, J.J., 2021. Acoustic retrofit strategies of windows in facades of residential buildings: Requirements and recommendations to reduce exposure to environmental noise. Journal of Building Engineering, 41, pp.102773. Doi: 10.1016/J.JOBE.2021.102773

13. Dissanayake, D.G.K., Weerasinghe, D.U., Thebuwanage, L.M., and Bandara, U.A.A.N., 2021. An environmentally friendly sound insulation material from post-industrial textile waste and natural rubber. Journal of Building Engineering, 33, pp.101606. Doi: 10.1016/J.JOBE.2020.101606

14. Glé, P., Massossa-Telo, G., Hellouin de Menibus, A., DegraveLemeurs, M., and Gourdon, E., 2021. Characterization and modelling of the sound reduction of hemp-clay walls in buildings. Journal of Building Engineering, 40, pp.102315. Doi: 10.1016/J.JOBE.2021.102315

15. Hasan, S., Usmani, J.A., and Islam, M., 2018. Simulation of Energy Conservation in a Building: A Case Study. Iranian (Iranica) Journal of Energy \& Environment, 9(1), pp.10-15. Doi: 10.5829/IJEE.2018.09.01.02

16. Deli, A.A., 2017. Natural frequency response to the angle and size of oblique crack in an isotropic hyper composite beam. International Journal of Energy \& Environment, 8(6), pp.523-536

17. Ibrahim Mohammed, K., and Mohammed Younus, Y., 2019. Experimental investigation into the effect of erosion and corrosion in pipes conveying fluid on its frequencies. International Journal of Energy and Environment, 10(1), pp.2076-2909

18. Kazemian, M.E., Gandjalikhan Nassab, S.A., and Jahanshahi Javarana, E., 2021. Techno-economic Optimization of Combined Cooling, Heat and Power System Based on Response Surface Methodology. Iranian (Iranica) Journal of Energy \& Environment, $12(4), \quad$ pp.285-296. Doi: 10.5829/IJEE.2021.12.04.02

19. Anju, G., Subha, B., Muthukumar, M., and Sangeetha, T., 2019. Application of Response Surface Methodology for Sago Wastewater Treatment by Ozonation. Iranian (Iranica) Journal of Energy \& Environment, 10(2), pp.96-103. Doi: 10.5829/IJEE.2019.10.02.05

\section{COPYRIGHTS}

(C)2021 The author(s). This is an open access article distributed under the terms of the Creative Commons Attribution (CC BY 4.0), which permits unrestricted use, distribution, and reproduction in any medium, as long as the original authors and source are cited. No permission is required from the authors or the publishers. 
طراحى آكوستيك مناسب به ويزه در برخى از ساختمانها اهميت دارد. به عنوان مثال در سالنهاى كنسرت يكى از ويزگى هاى كاربردى مطلوب، انتقال صحيح

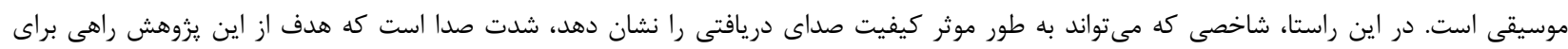

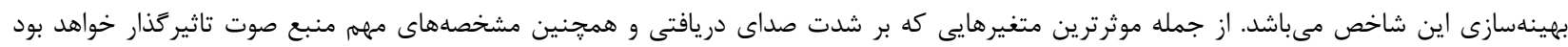

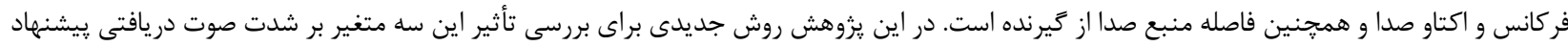

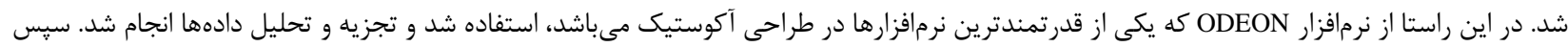



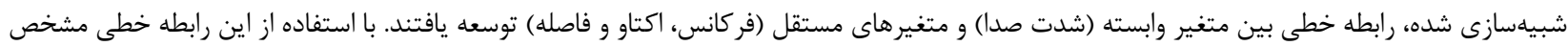

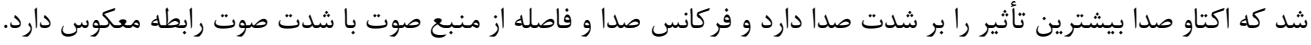

